\title{
Incidence and aetiology of eosinophilic pleural effusion
}

\author{
R. Krenke*, J. Nasilowski*, P. Korczynski*, K. Gorska*, T. Przybylowski*, \\ R. Chazan* and R.W. Light ${ }^{\#}$
}

ABSTRACT: Although eosinophilic pleural effusion (EPE) has been a subject of numerous studies, its clinical significance still remains unclear. The aim of our study was to evaluate: 1) the relative incidence and aetiology of EPE; 2) the predictors of malignancy in patients with EPE; and 3 ) the relationship between repeated thoracentesis and pleural fluid eosinophilia.

A retrospective analysis of 2,205 pleural fluid samples from 1,868 patients treated between 1995 and 2007 was performed.

We identified 135 patients with EPE (7.2\% of all patients with pleural effusion) and 153 EPE samples. The most common condition associated with EPE was malignancy (34.8\%) followed by infectious (19.2\%), unknown (14.1\%), post-traumatic $(8.9 \%)$ and miscellaneous $(23.0 \%)$ pleural effusions. The incidence of malignancy was significantly higher in patients with a lower $(\leqslant 40 \%)$ pleural fluid eosinophil percentage. 40 patients with EPE underwent a second thoracentesis. In 16, eosinophilia was present in both pleural fluid samples, 14 revealed pleural fluid eosinophilia only after the second thoracentesis and $\mathbf{1 0}$ had eosinophilia only in the first pleural fluid sample.

Pleural fluid eosinophilia should not be regarded as a predictor of nonmalignant aetiology. Probability of malignancy is lower in effusions with a high eosinophil percentage. The incidence of EPE in patients undergoing second thoracentesis is not different to that found during the first thoracentesis.

KEYWORDS: Eosinophilic pleural effusion, eosinophils, pleural effusion, pleural fluid, pleural fluid eosinophilia

osinophilic pleural effusion (EPE) is usually defined as a pleural effusion (PE) that contains $\geqslant 10 \%$ of eosinophils [1, 2]. The relative incidence of EPE has been estimated at between $5 \%$ and $16 \%$ of all PEs [1, 3-5], but the clinical significance of pleural fluid eosinophilia remains unclear. Some early studies have shown that pleural fluid eosinophilia is associated with a decreased risk of a malignant aetiology [1]. However, later studies did not confirm these observations [3-5]. Another interesting and unresolved issue is a potential causative relationship between the presence of air and/or blood in the pleural space and pleural fluid eosinophilia [1, 6-8].

Since pleural fluid eosinophilia is uncommon, our knowledge concerning EPE is based on small series and case reports. The majority of reports published before 1982 have been analysed by AdELMAN et al. [1]. However, the results of the studies published in the subsequent 15 yrs questioned some of the conclusions of their analysis.

To re-evaluate some of the important issues concerning EPE, we performed an analysis of a large series of samples of PE in our institution (Dept of Internal Medicine, Pneumology and Allergology Medical University of Warsaw, Warsaw, Poland). The specific goals of our study were to: 1) assess the relative incidence and aetiology of EPE; 2) search for the predictors of malignancy in patients with EPE; and 3) evaluate the relationship between the first and repeated thoracentesis and pleural fluid eosinophilia.

\section{MATERIALS AND METHODS}

A retrospective study of 2,205 pleural fluid samples from 1,868 consecutive patients with PE treated at the Medical University Hospital of Warsaw (a tertiary medical centre with 1,050 beds) between January 1995 and December 2007 was performed. Data from cytological and chemical examination of all pleural fluid samples were available. These included: specific gravity and $\mathrm{pH}$; pleural fluid and serum protein concentration; lactate dehydrogenase (LDH) activity in pleural fluid and in serum; pleural fluid glucose concentration; and total and differential cell count in PE.

\section{AFFILIATIONS}

*Dept of Internal Medicine, Pneumonology and Allergology, Medical University of Warsaw, Warsaw, Poland.

\#Division of Allergy, Critical Care Medicine and Pulmonary Diseases, Vanderbilt University, Nashville, TN, USA.

CORRESPONDENCE

R. Krenke

Dept of Internal Medicine, Pneumonology and Allergology Medical University of Warsaw ul. Banacha $1 \mathrm{~A}$ 02-097 Warsaw Poland E-mail: rafalkrenke@interia.pl

Received:

Dec 302008

Accepted after revision:

April 072009

First published online: April 222009 
Biochemical measurements were performed with an automated analyser (Cobas Integra 700; Roche Diagnostics, Rotkreuz, Switzerland, or Vitros 5,1 FS; Johnson \& Johnson, Langhorne, PA, USA). The ranges of normal values for serum were as follows: $\mathrm{pH}$ : 7.35-7.45; glucose: $65-105 \mathrm{mg} \cdot \mathrm{dL}^{-1}$; total protein: $62-82 \mathrm{G} \cdot \mathrm{dL}^{-1}$; LDH: $313-618 \mathrm{U} \cdot \mathrm{L}^{-1}$.

Until 1997, the pleural fluid red blood cell (RBC) and nucleated cell counts were measured by manual microscopy (Bürker hemocytometer) but since then an automated method has been used (Cell-Dyn 3700; Abbott Laboratories, Abbott Park, IL, USA, or Sysmex K-4500 and XT-2000; Sysmex Corporation, Kobe, Japan). The differential nucleated cell counts in pleural fluid were assessed by manual counting of 200 cells on a Papanicolaou-stained smear after cell concentration by cytocentrifugation $(450 \times g$ for $10 \mathrm{~min})$.

EPE was defined as pleural fluid containing $\geqslant 10 \%$ of eosinophils. If two (or more) thoracenteses were performed in the same patient and more than one pleural fluid sample met the EPE criterion the results of the first pleural fluid laboratory study were taken for analysis. Medical records of all patients with EPE were analysed and a database was created. The aetiology of the PE was established based on the medical history, physical examination, imaging studies, laboratory findings and the results of pleural fluid and pleural biopsy examination. In some cases the results of post mortem studies were available.

Effusions were classified as transudate or exudate using Light's criteria, and serum-effusion albumin gradient criterion in some doubtful cases of exudates [9-11].

\section{Definitions}

The specific aetiology of transudative effusions (congestive heart failure, liver cirrhosis and nephrotic syndrome) was based on clinical and laboratory data, as well as negative cytology and microbiology of the pleural fluid [12, 13].

Malignant PE was diagnosed in patients who had: 1) a positive pleural fluid cytology and/or positive histology of pleural biopsy (proven malignant effusion); or 2) a known malignant disease, after the exclusion of alternative causes of PE (probable malignant effusion) [8].

Tuberculous pleuritis was diagnosed in patients with a positive culture for Mycobacterium tuberculosis in pleural fluid, pleural biopsy or respiratory samples (sputum, bronchial washing and bronchoalveolar lavage fluid) and/or those with granulomas in pleural biopsy samples [14].

Parapneumonic effusion/emphysema was diagnosed in patients with typical signs and symptoms (acute febrile illness and pleuritic pain), pulmonary infiltrates on chest radiographs and no other explanation for PE [13, 15].

Post-traumatic effusion was diagnosed in cases of PE developing after chest trauma with no other explanation.

Connective tissue diseases (CTD) were diagnosed in patients with a known specific CTD after the exclusion of other causes of PE.

Pleural fluid of unknown origin was diagnosed when all the diagnostic procedures mentioned above failed to identify the aetiology of the PE. These patients were followed up to ensure there were no recurrences of PE.

\section{Statistical analysis}

Statistical analysis was performed using STATISTICA 8.0 software (StatSoft Inc., Tulsa, OK, USA). Data are presented as mean \pm SD when the data were normally distributed and median (interquartile range; IQR) when the data were not normally distributed. A t-test for unpaired samples was applied to test for significance between different groups. Whenever the variable did not show a normal distribution, nonparametric tests (MannWhitney U-test or Wilcoxon signed-rank test) were applied. The Spearman's rank correlation coefficient was applied to test correlations between pleural fluid eosinophils (percentage and number) and various clinical and cytological parameters of pleural fluid. The Chi-squared test was used to assess the proportions of patients with malignant versus unknown PEs in groups with different levels of pleural fluid eosinophilia. Receiver operating characteristic (ROC) analysis was performed to quantify the accuracy of various parameters to discriminate between malignant and benign EPEs, and between malignant EPEs and EPEs of unknown origin. A p-value $<0.05$ was considered as significant.

\section{RESULTS}

Pleural fluid eosinophilia was found in 153 pleural fluid samples (6.9\% from 2,205 samples). EPEs were identified in 135 $(7.2 \%)$ out of 1,868 patients. There were 146 EPEs classified as exudates and seven as transudates.

\section{Characteristics of patients with EPE}

There were $88(65 \%)$ males and 47 females in the EPE group and the male to female ratio of nearly 2:1 was higher than that for all patients with PE seen during the study period (1.2:1). The mean age of patients in the EPE group was $63.0 \pm 16.8 \mathrm{yrs}$ (range 21-96 yrs). 132 patients had unilateral PE: 67 (50\%) right-sided and 65 (48\%) left-sided. Bilateral PEs were found in three $(2 \%)$ patients, and two of them had bilateral pleural fluid eosinophilia.

The median (IQR) percentage of eosinophils in EPE (22.0 (14.5-43.5)) was significantly higher than the percentage of eosinophils in peripheral blood (5.0 (2.5-8.0); $\mathrm{p}<0.05)$. The percentage of eosinophils was higher in peripheral blood than in PE in only two patients. Both these patients had haematological malignancies. The median (IQR) eosinophil count in the pleural fluid $\left(402.5(188.8-920.0)\right.$ cells $\left.\times 10^{6} \cdot \mathrm{L}^{-1}\right)$ was similar to that in peripheral blood (426.7 $(190.5-720.8)$ cells $\times 10^{6} \cdot \mathrm{L}^{-1}$; NS). The distribution of pleural fluid eosinophil percentage is shown in figure 1.

In $45 \%$ of the patients, eosinophils accounted for $<20 \%$ of cells in PE. 40 patients $(30 \%)$ had peripheral blood eosinophilia (defined as the number of eosinophils exceeding 450 cells $\left.\times 10^{9} \cdot \mathrm{L}^{-1}\right)$.

\section{Aetiology of EPEs}

The aetiological distribution of EPEs is shown in table 1. The most frequent condition associated with pleural eosinophilia was malignancy (47 (34.8\%) out of 135 patients) followed by pleural infections (26 (19.3\%) patients), chest trauma (12 (8.9\%) patients) and various medical and surgical procedures (six 


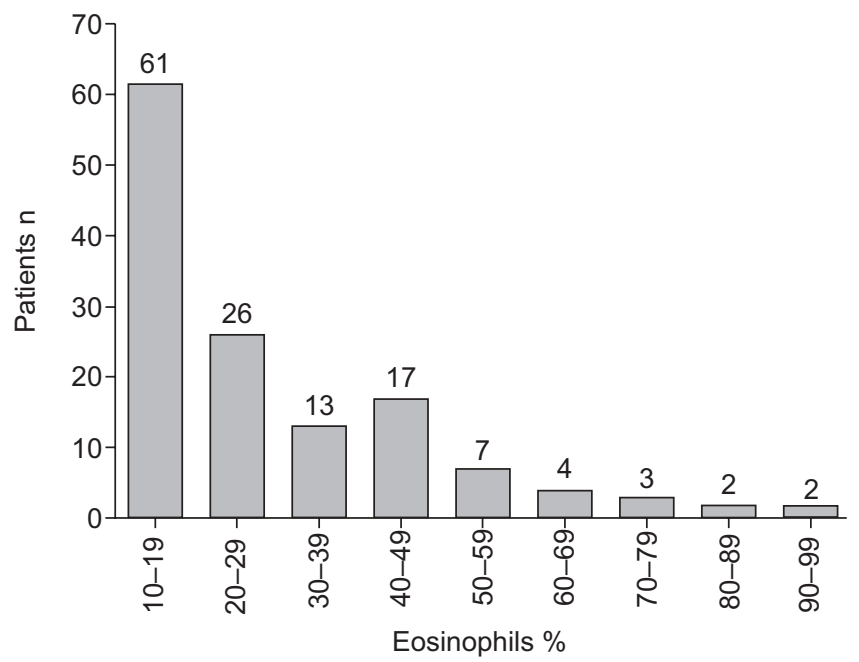

FIGURE 1. Distribution of eosinophil percentage in 135 patients with eosinophilic pleural effusion.

$(4.4 \%)$ patients). There were seven patients with pleural transudates who met the criterion of EPE, and five patients with EPE related to spontaneous pneumothorax.

In $19(14.1 \%)$ out of 135 patients the aetiology of the EPE remained unknown despite extensive diagnostic evaluation (11 underwent closed pleural biopsy, four medical thoracoscopy, and in four the amount of pleural fluid was small and did not recur after the first thoracentesis). None of these patients had a history of asbestos exposure or treatment with drugs known to cause EPE. 16 out of the 19 patients with EPE of unknown origin were followed up (mean follow-up time 9.2 months). Spontaneous resolution of EPE was found in all of the 16 pateints. Two out of the 16 patients died within 3 yrs of observation (for reasons unknown but unrelated to PE). Data concerning the remaining three patients who were not followed up were not available.

Lung cancer accounted for almost half of all malignant EPEs (23 (49\%) out of 47 patients) (table 1). The other sites of the primary tumour are listed in table 1 . In four patients $(9.8 \%$ of all patients with malignant EPE) the primary tumour site had not been identified.

Comparative analysis of patients with malignant versus nonmalignant EPE showed that patients with malignant EPE were significantly older, had a lower percentage of eosinophils in the peripheral blood and had a higher LDH in pleural fluid $(\mathrm{p}<0.05)$ (table 2$)$. The results of ROC analysis of the parameters which were found to be significantly different in malignant and non-malignant EPEs are presented in table 3.

A similar analysis for patients with malignant EPE and patients with EPE of unknown origin revealed that the latter were significantly younger and had a significantly higher eosinophil percentage in PE and in peripheral blood (data not shown).

The percentage of patients with malignant EPE was inversely related to the percentage of eosinophils in PE. The proportion of patients with malignant EPE decreased from 39.3\% in

\begin{tabular}{|c|c|c|}
\hline TABLE 1 & $\begin{array}{l}\text { Aetiological distribution of eosinophil } \\
\text { effusion }\end{array}$ & pleural \\
\hline \multicolumn{2}{|l|}{ Malignancy } & $47(34.8)$ \\
\hline \multicolumn{2}{|c|}{ Lung carcinoma } & $23(17)$ \\
\hline \multicolumn{2}{|c|}{ Unknown primary site } & 4 \\
\hline \multicolumn{2}{|c|}{ Breast carcinoma } & 3 \\
\hline \multicolumn{2}{|c|}{ Uterine corporeal carcinoma } & 2 \\
\hline \multicolumn{2}{|c|}{ Malignant mesothelioma } & 2 \\
\hline \multicolumn{2}{|c|}{ Non-Hodgkin lymphoma } & 2 \\
\hline \multicolumn{2}{|c|}{ Thyroid carcinoma } & 1 \\
\hline \multicolumn{2}{|c|}{ Pancreatic carcinoma } & 1 \\
\hline \multicolumn{2}{|c|}{ Prostate carcinoma } & 1 \\
\hline \multicolumn{2}{|c|}{ Urethelial carcinoma } & 1 \\
\hline \multicolumn{2}{|c|}{ Multiple myeloma } & 1 \\
\hline \multicolumn{2}{|c|}{ Chronic myeloid leukaemia } & 1 \\
\hline \multicolumn{2}{|c|}{ Malignant melanoma } & 1 \\
\hline \multicolumn{2}{|c|}{ Malignant fibrohistiocytoma } & 1 \\
\hline \multicolumn{2}{|c|}{ Ampulla of Vater carcinoma } & 1 \\
\hline \multicolumn{2}{|c|}{ Cholangiocarcinoma } & 1 \\
\hline \multicolumn{2}{|c|}{ Combined hepatocellular/cholangiocellular carcinoma } & 1 \\
\hline \multicolumn{2}{|l|}{ Infections } & $26(19.3)$ \\
\hline \multicolumn{2}{|c|}{ Parapneumonic effusion } & $23(17.0)$ \\
\hline \multicolumn{2}{|c|}{ Tuberculosis } & 3 \\
\hline \multicolumn{2}{|c|}{ Unknown } & $19(14.1)$ \\
\hline \multicolumn{2}{|c|}{ Post traumatic } & $12(8.9)$ \\
\hline \multicolumn{2}{|c|}{ Medical or surgical procedures } & $6(4.4)$ \\
\hline Post by-pa & s surgery & 2 \\
\hline Central vei & cannulation & 1 \\
\hline Thoracotor & & 1 \\
\hline Splenector & & 1 \\
\hline Oesophag & al sclerotherapy & 1 \\
\hline Transudativ & pleural effusions & $7(5.2)$ \\
\hline Congestive & heart failure & 4 \\
\hline Nephrotic & yndrome & 2 \\
\hline Hepatic hy & Irothorax & 1 \\
\hline Spontaneou & pneumothorax & $5(3.7)$ \\
\hline Pancreatic c & isease & $3(2.2)$ \\
\hline Acute panc & eatitis & 2 \\
\hline Pancreatic & Dseudocyst & 1 \\
\hline Pulmonary & mbolism & $3(2.2)$ \\
\hline Autoimmune & diseases & $2(1.5)$ \\
\hline Rheumatoi & arthritis & 1 \\
\hline Ulcerative & olitis & 1 \\
\hline Subphrenic & abscess & $1(0.7)$ \\
\hline Spontaneou & haemothorax (warfarine overdose) & $1(0.7)$ \\
\hline Dressler syr & drome & $1(0.7)$ \\
\hline Gorham syn & Irome & $1(0.7)$ \\
\hline $\begin{array}{r}\text { Recurrent e } \\
\text { due to Ho }\end{array}$ & $\begin{array}{l}\text { usion in patient after mediastinal irradiation } \\
\text { Igkin's lymphoma }\end{array}$ & $1(0.7)$ \\
\hline
\end{tabular}

Data are presented as $\mathrm{n}$ or $\mathrm{n}(\%)$.

patients with an eosinophil percentage of $10-20 \%$ to $16.6 \%$ in patients with an eosinophil percentage of $\geqslant 50 \%$. An opposite relationship was found for patients with PE of unknown origin (8.2\% in PEs with an eosinophil percentage of $10-20 \%$, but $33.3 \%$ in PEs with an eosinophil percentage of $\geqslant 50 \%$ ). ROC analysis revealed that the most accurate cut-off level to discriminate between malignant and non-malignant EPE 


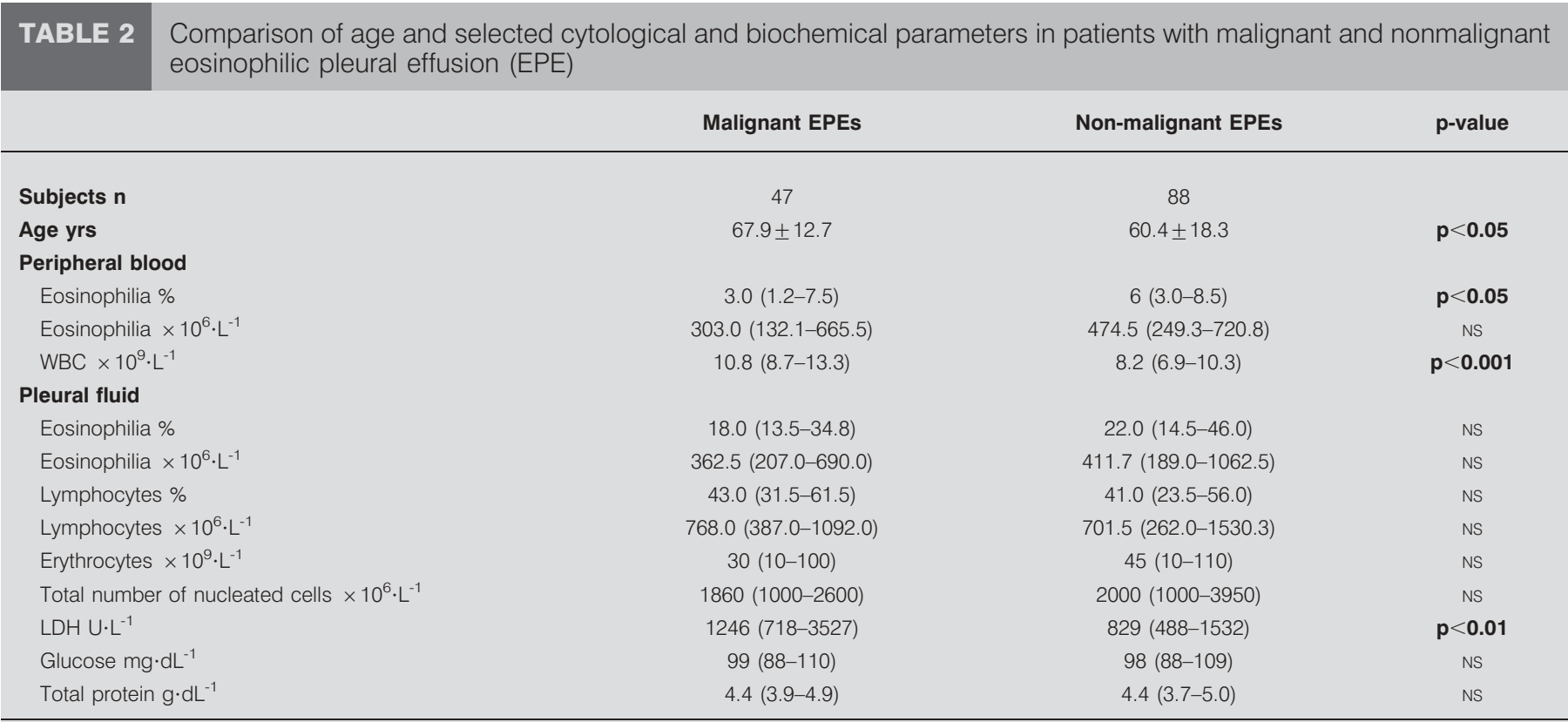

Data are presented as mean \pm SD or mean (interquartile range), unless otherwise stated. WBC: white blood cells; LDH: lactate dehydrogenase; NS: nonsignificant. The data in bold mark significance.

aetiology was an eosinophil percentage of $40 \%$. With the cutoff value for an eosinophil percentage of $40 \%$, the incidence of malignancy was found to be significantly higher in patients with low $(\leqslant 40 \%)$ eosinophil percentage PEs. The opposite relationship was found for patients with EPE of unknown aetiology (table 4). The sensitivity and specificity of differentiation between malignant versus non-malignant EPE aetiology on the basis of eosinophil percentage (cut-off level at $40 \%$ ) was estimated as $85.1 \%$ and $34.3 \%$, respectively.

\section{Pleural fluid eosinophilia and the number of thoracenteses} 40 patients with EPE underwent repeated thoracentesis. In 16, eosinophilia was present in both pleural fluid samples, while 14 had pleural fluid eosinophilia only after the second thoracentesis. An opposite relationship (eosinophilia only in the first pleural fluid sample) was noted in 10 patients.

Repeated thoracentesis was performed in 249 patients out of the 1,868 patients with PE (249 paired pleural fluid samples were analysed). The median (IQR) of eosinophil percentage in the first and the second fluid samples was $0.5(0-3)$ and $0.5(0$ 2.875), respectively (NS).

\section{Pleural fluid eosinophilia and other clinical and laboratory parameters}

We were not able to find any noteworthy correlations between eosinophils (percentage or number) in PE and other clinical and laboratory parameters. There was only a weak correlation between eosinophil percentage in $\mathrm{PE}$ and peripheral blood $(\mathrm{r}=0.28 ; \mathrm{p}<0.05)$ but no correlation between eosinophil count in PE and peripheral blood (NS). There was no significant correlation between the RBC count in PE and pleural fluid eosinophils (percentage or count).

\section{DISCUSSION}

This retrospective study including all patients with PE who underwent pleural fluid analysis in a large teaching hospital between 1995 and 2007 identified 135 patients with EPE. To

TABLE 3 The results of the receiver operating characteristic analysis for parameters with potential discriminative value between malignant and non-malignant eosinophilic pleural effusions

\begin{tabular}{|c|c|c|c|c|c|c|c|c|}
\hline & $\begin{array}{c}\text { Accurate cut-off } \\
\text { level }\end{array}$ & $\begin{array}{c}\text { Sensitivity } \\
\text { (95\% Cl) }\end{array}$ & $\begin{array}{c}\text { Specificity } \\
(95 \% \mathrm{Cl})\end{array}$ & PLR & NLR & PPV & NPV & p-value ${ }^{\#}$ \\
\hline Age yrs & $>62$ & $74.5(59.6-86.0)$ & $51.1(40.2-61.9)$ & 1.52 & 0.5 & 44.9 & 78.9 & 0.02 \\
\hline Eosinophils blood \% & $\leqslant 5$ & $72.2(54.8-85.8)$ & $56.1(42.4-69.3)$ & 1.65 & 0.49 & 51.0 & 76.2 & 0.04 \\
\hline WBC blood $\times 10^{9} \cdot \mathrm{L}^{-1}$ & $>8.6$ & $76.3(59.8-88.5)$ & $58.3(46.1-69.8)$ & 1.83 & 0.41 & 49.2 & 82.4 & 0.0005 \\
\hline LDH pleural fluid $U \cdot L^{-1}$ & $>929$ & $66.0(50.7-79.1)$ & $57.1(45.9-67.9)$ & 1.54 & 0.6 & 46.3 & 75 & 0.008 \\
\hline
\end{tabular}

PLR: positive likelihood ratio; NLR: negative likelihood ratio; PPV: positive predictive value; NPV: negative predictive value: WBC: white blood cells; LDH: lactate dehydrogenase. ${ }^{*}:$ area $=0.5$. 


\begin{tabular}{|c|c|c|c|c|c|c|}
\hline TABLE 4 & \multicolumn{6}{|c|}{$\begin{array}{l}\text { Patients with malignant pleural effusion (PE) and unknown PE in relation to eosinophilic pleural effusions (EPE) with low } \\
(\leqslant 40 \%) \text { and high }(>40 \%) \text { percentage of eosinophils }\end{array}$} \\
\hline \multicolumn{2}{|c|}{ Eosinophils in PE \% } & Subjects $n$ & Patients with malignant EPE & p-value & Patients with EPE of unknown origin & p-value \\
\hline \multicolumn{2}{|l|}{$\leqslant 40$} & 100 & $40(40)$ & $<0.05^{\#}$ & $9(9)$ & $<0.05^{\circ}$ \\
\hline \multicolumn{2}{|l|}{$>40$} & 35 & $7(20)$ & $<0.05^{\#}$ & $10(28.5)$ & $<0.05^{\circ}$ \\
\hline
\end{tabular}

Data are presented as $n(\%)$, unless otherwise stated. ${ }^{*}$ : patients with malignant EPE versus non-malignant EPE (Chi-squared test); ": patients with EPE of unknown origin versus EPE of known origin (Chi-squared test).

our knowledge, this is the largest single study group published in the English language literature [2]. A larger group of 172 patients, treated in Saint Thomas Hospital (Nashville, TN, USA), has been mentioned in the review by KALOMENIDIS and LiGHT [2] but only very few data were presented.

In our study, patients with EPE comprised $7.2 \%$ of all patients with PE, and $6.9 \%$ of all PEs were eosinophilic. Thus, the incidence of EPE was similar to that reported by ADELMAN et al. [1] but slightly lower than that found in three studies published between 1989 and 2000 (table 5) [3-5]. The ratio of males to females in the EPE group (2:1) was higher than that for all analysed patients with PE (1.2:1). This finding is consistent with the results of WYSENBEEK et al. [7] (42\% females in the EPE group). The male to female ratio observed in other studies was as high as 9:1 [16]. A possible explanation for the very high ratios is a higher prevalence of males with PEs seen at some institutions [5].

EPE can be associated a with wide range of underlying conditions, including: infections (e.g. bacterial, parasitic or fungal), malignancies, autoimmune diseases, drug reactions, pulmonary embolism, chest trauma and many others [2]. In the present study, malignancy was the most common aetiology associated with EPE, being responsible for $34.8 \%$ of cases. If we exclude the patients with pleural transudates the percentage of patients with malignant EPE rises to $37 \%$, which is similar to that found by KUHN et al. [3]. A vast majority of malignant
EPEs was related to solid tumours (43 (92\%) out of 47). Only four patients with haematological malignancies developed pleural fluid eosinophilia. This could be explained by a similar distribution of the primary tumour site in all patients with malignant PE treated in our hospital. Half of the malignant EPEs were related to lung cancer (table 1). Surprisingly, breast cancer was found in only four patients, despite the fact that there were 17 females in the malignant EPE group. In four $(10.7 \%)$ cases the primary site of cancer remained unknown, and this percentage is similar to the proportion of patients with unknown primary site of tumour to all patients with malignant PEs found by other authors (5-10\%) [17].

The current study confirmed the results of three studies performed in the last two decades [3-5], which showed that $22.7-40.1 \%$ of EPEs have a malignant aetiology (table 5). The aetiological distribution of EPEs reported in various studies is presented in table 5 .

An interesting observation in this study was an inverse relationship between the percentage of eosinophils in PE and the proportion of patients with malignant PE. The proportion of patients with malignant PE decreased to $16.6 \%$ of patients with EPE containing at least $50 \%$ of eosinophils. This decrease was paralleled by a rise in the percentage of patients with unknown pleural fluid aetiology. Most previous studies have not addressed this issue. KUHN et al. [3] reported that three patients had eosinophils exceeding $50 \%$ and none was

TABLE 5 Aetiology of eosinophilic pleural effusions (EPE)

\begin{tabular}{|c|c|c|c|c|c|c|c|c|c|}
\hline $\begin{array}{l}\text { First author } \\
\text { [ref.] }\end{array}$ & $\begin{array}{c}\text { Patients } \\
\text { with EPE } n\end{array}$ & $\begin{array}{l}\text { Patients with } \\
\mathrm{EPE} / \text { all patients } \\
\text { with } \mathrm{PE} \%\end{array}$ & Malignant & $\begin{array}{c}\text { Para- } \\
\text { pneumonic }\end{array}$ & Tuberculous & $\begin{array}{l}\text { Post- } \\
\text { traumatic }\end{array}$ & CHF & CTD & Unknown \\
\hline AdeLmAn [1] & $343^{\circ}$ & $5-8$ & $27(8)$ & $21(6)^{+}$ & $14(4)$ & $17(5)$ & $6(2)$ & $15(4)$ & $119(35)$ \\
\hline Wysenbeek [7] & 36 & NA & $12(33)$ & $3(8.5)$ & 0 & $9(25)$ & $5(14)$ & 0 & $3(8.5)$ \\
\hline Rubins [5] & 44 & 9.2 & $10(22.7)$ & $4(9.1)$ & 0 & 0 & $6(13.6)$ & 0 & $11(25)$ \\
\hline MARTINEZ-Garcia [4] & 45 & 12 & $11(24.4)$ & $15(33.3)^{5}$ & $7(15.6)$ & 0 & 0 & 0 & $7(15.6)$ \\
\hline Present study & 135 & 7.2 & 47 (34.8) & $23(17)$ & $3(2.2)$ & $12(8.9)$ & $4(3)$ & $2(1.5)$ & $19(14.1)$ \\
\hline Total $^{\#}$ & 711 & NA & $123(17.3)$ & $75(10.5)$ & $59(8.3)$ & $44(6.2)$ & $26(3.7)$ & $19(2.7)$ & $181(25.5)$ \\
\hline
\end{tabular}

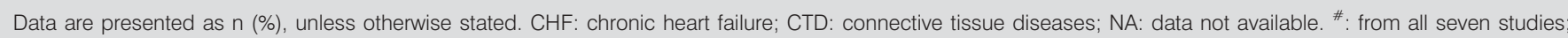
$\because$ : summary of 22 studies; ${ }^{+}$: parapneumonic effusion and emphysema, together; ${ }^{\S}$ : uncomplicated, complicated, together; ${ }^{f}$ : heart and renal failure, together. 
malignant, although $40 \%$ of their EPEs were malignant. Our ROC analysis showed that pleural fluid eosinophil percentage has a relatively high sensitivity but very low specificity in discriminating between malignant and non-malignant EPEs. The clinical usefulness of such a test is very limited. Nevertheless, these numbers show that as many as $85 \%$ of all malignant EPEs could be expected to have a pleural fluid eosinophil percentage $<40 \%$. ROC analysis confirmed that the patient's age, white blood cell count, blood eosinophil percentage and pleural fluid LDH activity might be of some value in discriminating between malignant and non-malignant EPEs. However, since the sensitivity of these parameters ranges between $65 \%$ and $75 \%$ and the specificity is even lower, none of these parameters could serve as a reliable test to differentiate between malignant and benign EPE.

Interestingly, the number of RBCs were virtually the same in malignant and non-malignant EPEs. This might be of valuable clinical information suggesting that malignant aetiology of EPE should be considered irrespectively of the fluid blood content. Furthermore, we were not able to find a relationship between the percentage of eosinophils and the number of RBCs in PE.

The second largest group of patients with EPE consisted of patients with pleural and/or pulmonary infections. 23 patients had a parapneumonic effusion, while only three patients had tuberculous PE. Eosinophilia in parapneumonic effusion has been noted by many authors. ADELMAN et al. [1] reported that parapneumonic effusion accounted for $6 \%$ of EPEs. Similar results were found by KAMEL et al. [16] (6.9\%), WYSENBEEK et al. [7] (8.5\%), and RUBINS and RUBINS [5] (9.1\%). MARTINEZ-GARCIA et al. [4] reported that parapneumonic effusions accounted for $33.3 \%$ of all EPEs (table 5). The explanation for the very high percentage of parapneumonic effusions in the latter study is unknown.

Although tuberculosis is thought to be a rare cause of EPE [8], MARTínEZ-GARCíA et al. [4] and KAMEL et al. [16] reported that tuberculous pleurisy was responsible for $15.6 \%$ and $39.6 \%$ of cases of EPE, respectively (table 5). The study of KAMEL et al. [16] was performed in Tunisia, a country with a very high incidence of tuberculous pleurisy, and this probably explains their high proportion of patients with tuberculous EPE. In our patients with EPE only $2.2 \%$ had tuberculous pleurisy. In all patients with PE treated in our hospital between 2001 and 2007 tuberculosis was responsible for $\sim 5 \%$ of cases.

In $19(14.1 \%)$ patients, the aetiology of EPE could not be established. Most experts agree that in 10-20\% of patients with $\mathrm{PE}$ the underlying condition remains unknown [8, 18]. This percentage might be even higher in patients with EPE. In the study of RUBINS and RUBINS [5], PE of unknown origin was significantly more frequent in patients with EPEs than in the non-EPE group. A similar trend was observed in a study by MARTínEZ-GARCíA et al. [4], although the difference was not statistically significant.

Pleural fluid eosinophilia seems to be a relatively common finding in post-traumatic PE including PE following thoracic surgery. Differences in the proportion of patients with posttraumatic EPE are probably related to the number of post-trauma patients seen at different institutions. In the study by WYSENBEEK et al. [7], 25\% of EPE cases were related to chest trauma. In contrast, RUBINS and RuBINS [5], as well as MARTíNEZ-GARCíA et al.
[4], did not identify any case of chest trauma-related EPE (table 5). In our study, chest trauma was the fourth leading condition associated with pleural fluid eosinophilia, and was noted in $12(8.9 \%)$ patients. Eosinophilia in this situation is induced by local synthesis of interleukin (IL)-5 by CD4+lymphocytes, as well as some mechanisms involving local activation of the classic pathway of complement $[19,20]$.

Similar mechanisms might play a role in EPE formation in patients undergoing coronary artery and/or cardiac surgery [21]. IL-5 and vascular cell adhesion molecule- 1 are probably the most important factors involved in the development of EPE in patients undergoing coronary artery bypass grafting (CABG) [22-25]. The prevalence of $\mathrm{PE}$ in these patients might be as high as 63\% [26]. However, only "early effusions" (developing <30 days after $\mathrm{CABG}$ ) were shown to contain a high number of eosionophils, whereas lymphocyte predominance was noted in the "late effusions" (developing $>30$ days after CABG) [27].

It is noteworthy that different forms of chest trauma (iatrogenic and non-iatrogenic) are often associated with the pneumothorax. It has been demonstrated that air in the pleural space can stimulate eosinophilic pleural inflammation. Therefore, it is often difficult to determine which mechanism (trauma per se, blood or air in the pleural space) is responsible for EPE in a particular patient. IL-5 also seems to be related to eosinophil accumulation in EPEs associated with the pneumothorax [28-31].

In the context of the potential causative relationship between blood/air in the pleural space and EPE, data on any pleural procedures preceding the diagnosis of EPE are of great importance. CHUNG et al. [32] reported an increase in the number of pleural fluid eosinophils in patients with malignant PE who underwent repeated thoracentesis (three pleural taps). CHUNG et al. [32] also found a significant increase in tumour necrosis factor- $\alpha$, IL-1 $\beta$, IL-8, vascular endothelial growth factor and plasminogen-activator inhibitor- 1 in patients with transudative PE undergoing repeated thoracenteses. Thus, they concluded that repeated thoracentesis may induce a local release of proinflammatory cytokines [33]. However, MARTINEZ-GARCIA et al. [34] did not find significant differences between the total number and percentage of eosinophils in pleural fluid samples collected during the first, second or subsequent taps from 120 patients. The results of our study are consistent with those of MARTINEZGARCIA et al. [34]. In our study, the incidence of new EPEs in patients undergoing a second thoracentesis was quite low (5.6\%). RUBINS and RUBINS [5] showed an even smaller percentage of EPE during the second pleural tap (2.3\%) and concluded that a repeated thoracentesis within 2-12 weeks reduced rather than produced EPE.

In summary, the present study shows that EPE should not be regarded as a predictor of a non-malignant aetiology. Since malignancies are responsible for more than one-third of EPEs, the diagnostic approach to EPE should be the same as for all other PE and should involve all diagnostic procedures including closed pleural biopsy and thoracoscopy, if necessary. However, probability of malignancy is significantly lower in effusions containing a high percentage of eosinophils. Repeated thoracentesis does not significantly increase the proportion of patients with EPE, and the incidence of EPE during the second thoracentesis is quite low. 


\section{STATEMENT OF INTEREST}

None declared.

\section{REFERENCES}

1 Adelman M, Albelda SM, Gottlieb J, et al. Diagnostic utility of pleural fluid eosinophilia. Am J Med 1984; 77: 915-920.

2 Kalomenidis I, Light RW. Eosinophilic pleural effusions. Curr Opin Pulm Med 2003; 9: 254-260.

3 Kuhn M, Fitting JW, Leuenberger P. Probability of malignancy in pleural fluid eosinophilia. Chest 1989; 9: 992-994.

4 Martinez-Garcia MA, Cases-Viedma E, Cordero-Rodriguez PJ, et al. Diagnostic utility of eosinophils in the pleural fluid. Eur Respir J 2000; 15: 166-169.

5 Rubins JB, Rubins HB. Etiology and prognostic significance of eosinophilic pleural effusions. A prospective study. Chest 1996; 110: 1271-1274.

6 Oda M, Satouchi K, Ikeda I, et al. The presence of plateletactivating factor associated with eosinophil and/or neutrophil accumulation in pleural fluids. Am Rev Respir Dis 1990; 141: 1469-1473.

7 Wysenbeek AJ, Lahav M, Aelion JA, et al. Eosinophilic pleural effusion: a review of 36 cases. Respiration 1985; 48: 73-76.

8 Light RW. Pleural diseases. 5th Edn. Wolters-Kluwer/Lippincott Williams \& Wilkins, Philadelphia, 2007.

9 Light RW, MacGregor MI, Luchsinger PC, et al. Pleural effusions: the diagnostic separations of transudates and exudates. Ann Intern Med 1972; 77: 507-513.

10 Porcel JM, Vives M, Vicente de Vera MC, et al. Useful tests on pleural fluid that distinguish transudates from exudates. Ann Clin Biochem 2001; 38: 671-675.

11 Romero-Candeira S, Hernández L. The separation of transudates and exudates with particular reference to the protein gradient. Curr Opin Pulm Med 2004; 10: 294-298.

12 Kinasewitz GT. Transudative effusions. Eur Respir J 1997; 10: 714-718.

13 Light RW. Diagnostic principles in pleural disease. Eur Respir J 1997; 10: 476-481.

14 Valdés L, Pose A, San José E, et al. Tuberculous pleural effusion. Eur J Intern Med 2003; 14: 77-88.

15 Hamm H, Light RW. Parapneumonic effusion and empyema. Eur Respir J 1997; 10: 1150-1156.

16 Kamel A, Chabbou A, El Gharbi B. [Apport diagnostique de l'eosinophilie pleurale.]. Rev Pneumol Clin 1989; 45: 118-122.

17 Marel M. Epidemiology of pleural effusion. In: Loddenkemper R, Antony VB, eds. Pleural Diseases. Eur Respir Mon 2002; 22: 146-156.

18 Ferrer JS, Muñoz XG, Orriols RM, et al. Evolution of idiopathic pleural effusion: a prospective, long-term follow-up study. Chest 1996; 109: 1508-1513.
19 Schandené L, Namias B, Crusiaux A, et al. IL-5 in post-traumatic eosinophilic pleural effusion. Clin Exp Immunol 1993; 93: 115-119.

20 de Blay F, Aykut-Baturalp A, Goetz J, et al. Post-traumatic pleural effusion: demonstration of local complement consumption. Respir Med. 1997; 91: 373-375.

21 Light RW. Pleural effusions after coronary artery bypass graft surgery. Curr Opin Pulm Med 2002; 8: 308-311.

22 Mohamed KH, Abdelhamid AI, Lee YC, et al. Pleural fluid levels of interleukin-5 and eosinophils are closely correlated. Chest 2002; 122: $576-580$.

23 Nakamura Y, Ozaki T, Kamei T, et al. Factors that stimulate the proliferation and survival of eosinophils in eosinophilic pleural effusion: relationship to granulocyte/macrophage colony-stimulating factor, interleukin-5, and interleukin-3. Am J Respir Cell Mol Biol 1993; 8: 605-611.

24 Kalomenidis I, Mohamed KH, Lane KB, et al. Pleural fluid levels of vascular cell adhesion molecule- 1 are elevated in eosinophilic pleural effusions. Chest 2003; 124: 159-166.

25 Kalomenidis I, Light RW. Pathogenesis of the eosinophilic pleural effusions. Curr Opin Pulm Med 2004; 10: 289-293.

26 Light RW, Rogers JT, Moyers JP, et al. Prevalence and clinical course of pleural effusions at 30 days after coronary artery and cardiac surgery. Am J Respir Crit Care Med 2002; 166: 1567-1571.

27 Sadikot RT, Rogers JT, Cheng DS, et al. Pleural fluid characteristics of patients with symptomatic pleural effusion after coronary artery bypass graft surgery. Arch Intern Med 2002; 160: 2665-2668.

28 Kalomenidis I, Guo Y, Peebles RS, et al. Pneumothorax-associated pleural eosinophilia in mice is interleukin-5 but not interleukin-13 dependent. Chest 2005; 128: 2978-2983.

29 Kalomenidis I, Moschos C, Kollintza A, et al. Pneumothoraxassociated pleural eosinophilia is tumour necrosis factor- $\alpha$ dependent and attenuated by steroids. Respirology 2008; 13: 73-78.

30 Smit HJ, van den Heuvel MM, Barbierato SB, et al. Analysis of pleural fluid in idiopathic spontaneous pneumothorax; correlation of eosinophil percentage with the duration of air in the pleural space. Respir Med 1999; 93: 262-267.

31 De Smedt A, Vanderlinden E, Demanet C, et al. Characterisation of pleural inflammation occurring after primary spontaneous pneumothorax. Eur Respir J 2004; 23: 896-900.

32 Chung CL, Chen YC, Chang SC. Effect of repeated thoracenteses on fluid characteristics, cytokines, and fibrinolytic activity in malignant pleural effusion. Chest 2003; 123: 1188-1195.

33 Chung CL, Yeh CY, Sheu JR, et al. Repeated thoracenteses affect proinflammatory cytokines, vascular endothelial growth factor, and fibrinolytic activity in pleural transudates. Am J Med Sci 2007; 334: 452-457.

34 Martinez-Garcia MA, Cases Viedma E, Perpiñá Tordera M, et al. Repeated thoracentesis: an important risk factor for eosinophilic pleural effusion? Respiration 2003; 70: 82-86. 